Portland State University

PDXScholar

\title{
Self-Management and Social Skills Training for Persons With Developmental Disabilities: Tools for the Rehabilitation Counselor to Facilitate Success in Community Settings: A Literature Review
}

Tina M. Anctil Peterman

Portland State University, anctil@pdx.edu

Charles Edmund Degeneffe

California State University - Fresno

Follow this and additional works at: https://pdxscholar.library.pdx.edu/coun_fac

Part of the Counseling Psychology Commons, and the Student Counseling and Personnel Services Commons

Let us know how access to this document benefits you.

\section{Citation Details}

Anctil, T.M., \& Degeneffe, C. (2003). Self-management and social skills training for persons with developmental disabilities: Tools for the rehabilitation counselor to facilitate success in community settings: A literature review. Journal of Applied Rehabilitation Counseling, 34, 17-24.

This Article is brought to you for free and open access. It has been accepted for inclusion in Counselor Education Faculty Publications and Presentations by an authorized administrator of PDXScholar. Please contact us if we can make this document more accessible: pdxscholar@pdx.edu. 


\title{
Self-Management and Social Skills Training for Persons with Developmental Disabilities: Tools for the Rehabilitation Counselor To Facilitate Success in Community Settings: A Literature Review
}

\author{
Tina M. Anctil \\ Charles Edmund Degeneffe
}

\begin{abstract}
People with developmental disabilities often display deficiencies in self-management and social skills in community based settings. Difficulties with self-management and social skills tend to pose particular difficulties for performing valued adult roles. Tools from behavior therapy have the potential to assist rehabilitation counselors in their work with consumers with developmental disabilities to overcome the negative impacts of functional limitations on expressing behaviors needed for success in community-based settings. This article presents a review of the behavior therapy literature regarding self-management and social skills training techniques rehabilitation counselors can use in their work with consumers with developmental disabilities in areas including high school transition and supported employment.
\end{abstract}

\section{Introduction}

The developmental disability classification was introduced by the federal government in the 1960 s to indicate disorders and diseases causing disability that impacted development early in life and necessitated services carrying out activities of everyday living (Pope \& Tarlov, 1991). Since that time, each state developed its own legal definitions of developmental disability derived from the federal definition. The federal Developmental Disabilities Assistance and Bill of Rights Act of 1994 (42 U. S.C.A. Sec. 6000 et seq.) defines developmental disability as follows:

A severe, chronic disability of a person which is: (a) attributable to a mental or physical impairments; (b) is manifested before age 22; (c) is likely to continue indefinitely; (d) results in substantial functional limitations in three or more of the following areas of life activity: (1) self-care, (2) receptive and expressive language, (3) learning, (4) mobility, (5) selfdirection, (6) capacity for independent living, (7) economic self-sufficiency, and, (8) reflects the person's need for a combination and sequence of special interdisciplinary or generic care, treatment or other services, which are lifelong or of extended duration and are individually planned and coordinated (U.S. Department of Health and Human Services, 1999).
Mental retardation, chronic health problems, cerebral palsy, autism, spinal cord injury, and severe head injury are developmental disabilities listed in the federal definition (U.S. Department of Health and Human Services, 1995). Demographic statisticians estimate that there are between $2,000,000$ and 4,000,000 persons with developmental disabilities in the United States (Pope \& Tarlov, 1991).

\section{Historical and Societal Perceptions and Responses}

Throughout history, persons with developmental disabilities have faced differing social attitudes and treatment. Prior to the 1960 s, large, state-operated institutions offered the primary service option for persons with developmental disabilities. Frequently placed in rural regions, institutions did not accord many community integrative opportunities (Braddock, 1998).

From the 1950 s through the 1970 s (i.e., the deinstitutionalization period), developmental disability advocates brought attention to the inhuman and socially restrictive conditions of many institutions (Lakin, Bruinicks, \& Larson, 1992). Throughout this period, institutional placements substantially reduced and community service options expanded (Bradley \& Knoll, 1990). For example, in 1954, the federal government passed Rehabilitation Act 
amendments that included persons with mental retardation as eligible recipients of vocational rehabilitation services (Braddock, 1998). Thereafter, segregated sheltered workshops provided the primary vocational services to persons with developmental disabilities (Shafer, 1989). Braddock (1998) stressed sheltered workshops were a service characterized by token wages and menial work.

The normalization (Wolfensberger, 1977) and consumer empowerment (Olney \& Salomone, 1992) movements of the $1980 \mathrm{~s}$ and $1990 \mathrm{~s}$ led to the development of integrated and inclusive community based services for persons with developmental disabilities. In this period, contemporary support approaches include supported employment (Degeneffe, 2000), supportive living initiatives (Lakin \& Smull, 1995), parent support services (Mandeville, 1990), family support programs (Braddock, Hemp, Parish, Westrich, \& Park, 1998), educational inclusion (York \& Tundidor, 1995), person-centered service coordination (Smull \& Danehey, 1994), and sexuality education (Heighway, Kidd-Webster, \& Shaw, 1992).

The original definition of behavior therapy as the application of learning theory (Eyenck, 1959) generated practical treatment methods but also represented what was then the most rigorous scientific approach to behavior change.

Behavior therapy emphasizes corrective leaming experiences in which clients acquire new coping skills, improve communication, or learn to break maladaptive habits and overcome self-defeating emotional conflicts....It involves both dynamic interaction between therapist and client and directed work on the part of the client (Wilson, 1995, p. 208).

The seminal significance of behavior therapy was commitment to apply the principles and procedures of experimental psychology to clinical problems, to rigorously evaluate the effects of intervention, and to ensure that clinical practice was guided by objective evaluations. Much of the services offered by rehabilitation agencies and personnel is oriented towards eliminating or reducing problematic behavior and bringing about more adaptive behavior. To these ends, the behaviorists view behavior, their implications and how to modify them in different ways.

Today, rehabilitation counselors need the perspective, skill, and experiential background to facilitate the full and inclusive participation of the consumers with developmental disabilities they assist to participate in a vast array of valued community-based roles. This intervention often focuses on behavioral training needed to enhance positive behaviors across various community environments (e.g., high school transition planning, supported employment). To address this topic, this article will address the following: (a) applications of behavior therapy for persons with developmental disabilities, (b) self-management training in high school transition, (c) social skills training in supported employment, and (d) pragmatic considerations in using behavior therapy in rehabilitation settings.

\section{The Role of the Rehabilitation Counselor and Behavior Intervention}

The focus of behavior training involving people with developmental disabilities has moved from traditional institutional settings to community inclusion settings, which has increased the many applications of behavior therapy to the field of rehabilitation. For the rehabilitation counselor, the goal of intervention is generally community employment (Rice, 1985) as well as success in independent living (Rubin \& Roessler, 1995). However, consumers often have many functional limitations that can affect their rehabilitation goals, such as deficits in communication and learning. Hence, rehabilitation counselors need to understand specific techniques that can be employed to assist young adults (i.e., the transition from high school into adulthood) with developmental disabilities to develop behavioral skills needed for success in community-based employment and independent living (Sands \& Wehmeyer, 1996).

Often, rehabilitation research on behavioral strategies with people with developmental disabilities originated within the sheltered workshop settings where investigations commonly addressed acquiring a vocational skill, increasing worker productivity, and decreasing maladaptive behaviors.

Nezu and Nezu (1994) reviewed operant procedures historically applied and evaluated in residential and institutional facilities. The research indicated operant procedures to be an efficacious intervention for adults with mental retardation experiencing a wide range of emotional and behavior disorders. These problems included fears and phobias, toileting problems, deficient speech skills, eating disorders, deficient self-help skills, obesity, anxiety disorders, aggression, conduct disorders, sociopathic behaviors, self-stimulation, self-injurious behaviors, rumative vomiting, specific behaviors symptomatic of schizophrenia and major depression, enuresis, encopresis, coprophagy, and specific behavioral deficits associated with autism (p. 35).

While behavioral studies were often effective in institutional settings, there are limitations to this approach today because of an inability to conduct the same type of behavioral research in community-based settings. Moreover, increased ethical and legal obstacles regarding consumers' rights to "least restrictive treatment" can encumber the application of interventions not explicitly made clear to persons with developmental disabilities. Maintenance of treatment effectiveness and generalization to new environments are also problematic. After reviewing the basic applied research in the field of mental retardation, Whitman (1990) concludes, "that the critical defining characteristic of persons with retardation is not their specific adaptive behavior or cognitive deficiencies per se, which can often be quickly remediated, but their inability to use what they have learned in nontraining situations" (p. 348). Matson and Gardner (1991) noted most studies of operant procedures with persons with mental retardation continue 
to follow the "train-and-hope" model for generalization and maintenance.

Correspondingly, respondent-based interventions, which are most commonly conducted in clinical and natural settings, address progressive muscle relaxation and systematic desensitization. Richard, Thrasher, and Elkins (1984) found that adults with mild or moderate mental retardation were able to understand and follow instructions related to relaxation training, including imagery components. Twenty adults, in four IQ ranges (IQ $40-54$; IQ $55-69 ; \mathrm{IQ} 70-84 ; \mathrm{IQ} 85-200$ ) were asked to respond to four forms of relaxation instruction: imagery; suggestions of relaxation; controlled breathing; and muscle tension/relaxation. The results suggest these four relaxation techniques were understood and used effectively with people with mental retardation. This may be particularly important to the consumer who is anxious about employment in the community or other changes which may affect his or her life, such as a new residence or a new employment setting.

The final behavior therapy intervention commonly used for persons with developmental disabilities is the social learning approach. These approaches include strategies such as participant modeling, behavioral rehearsal, self-reinforcement, and various cognitive-behavioral approaches including problem solving training, assertiveness training, self-instructional training, and social skills training. As reviewed by Nezu and Nezu (1994), numerous studies have found social skills training to be an effective approach to help increase interpersonal functioning and assertiveness. Today, in interventions for persons with developmental disabilities, behavior therapists often integrate cognitive principles and procedures into what is now widely known as cognitive behavioral therapy. Cognitive behavioral therapy is an amalgam of behavioral and cognitive strategies based on the assumption that performance-based procedures are the most effective means of producing change that is mediated by cognitive processes (Bandura, 1986). In describing this, Nezu and Nezu (1994) state:

On the basis of our literature review, we assert that behavioral approaches, especially those involving social learning and cognitive behavioral based strategies, are clearly the forerunners in providing studies of well-documented efficacy. Several investigations have included randomized group methodologies with well-defined populations, reliable measures (including the accurate diagnosis of mental retardation and psychiatric disorder), social validity measures, and adequate follow-up assessments. Unfortunately only a handful of such studies exist for outpatient treatment (p. 38).

Rehabilitation counselors may incorrectly assume that clinical gains through behavior therapy automatically transfer to the consumer's natural environment. Noting behavior therapy's application to rehabilitation counseling, Rice (1985) contends that rehabilitation counselors who understand the basic principles, background, and use of behavioral techniques are more likely to experience suc- cess with consumers with mental retardation. Today, behavior therapy techniques continue to have particular relevance for rehabilitation counselors who facilitate successful participation in community-based programs and services for consumers with developmental disabilities. Additionally rehabilitation counselors involved in the transition from high school to adult life or supported employment may find success with behavioral approaches.

\section{Useful Applications of Behavior Therapy Interventions with Developmental Disabilities}

Contemporarily, behavior therapy studies in general have moved from evaluating operant procedures, mostly in institutional settings, to respondent-based interventions focusing on social learning approaches conducted in community settings (Nezu \& Nezu, 1994). The latter approach includes the applications most useful to the rehabilitation counselor interested in strategies and tools needed for promoting success in community employment and independent living.

\section{Self-Management Training in High School Transition}

The transition from high school to adult life is a significant developmental milestone for all adolescents. However, for adolescents with disabilities this can be a particularly trying time. Thirty-one percent of adolescents with disabilities drop out of high school, a rate much higher than that of adolescents without disabilities (Phelps \& Hanley Maxwell, 1997; U.S. Department of Education, 2000 ). Unemployment rates for young women with disabilities are over four times the rates of young women without disabilities, while unemployment rates for young adult males with disabilities are approximately three times those of their peers without disabilities. Additionally, youth with disabilities attend postsecondary education or training at much lower rates than do young adults without disabilities (U.S. Department of Education, 2000).

Transition planning is one important area that has been identified to assist adolescents with disabilities build the skills and positive behaviors needed for success in the community and throughout adulthood (Parker \& Szymanski, 1998). Rehabilitation counselors have the experience and training to offer their expertise to transition teams members during transition planning. Within transition planning and preparation, self-management training can assist students with disabilities by decreasing the impact of disability related impairments (e.g., communication) while increasing the potential for personal growth (Sawyer \& Crimando, 1984). The self-management model is based on the assumption that the transition process requires a coordinated effort among key school personnel, family members, adult service providers, and the student him or herself. It is an ecological approach that assumes, "changes in any single arena of a student's life (e.g., residential, employment, family life, etc.) affect all other aspects of that individual's life" (Hughes \& Rusch, 1992, p. 210). For 
example, moving from a parent's home into an apartment living program may affect transportation, friendships, recreation, learning, and employment opportunities. Hughes and Rusch emphasized:

For these reasons, strategies designed to increase a student's self governing skills must be introduced simultaneously in multiple environments and take into account the reciprocity of changes that will occur across settings. Such a pluralistic approach to instruction promotes generalization of behavior management skills by providing multiple exemplars in which desired behaviors are expected to be performed (Homer, 1988; Stokes \& Baer, 1977). When a student has learned to use a particular behavior management technique (e.g. self-reinforcement) across several settings, the student will likely employ the technique under novel conditions (1992, p. 210).

Self-management training is a framework for many of the various behavior strategies and requires the consumer to be an active collaborator in the counseling and psychotherapeutic process. It is an outgrowth of operant conditioning and assists consumers in developing the ability to self regulate their behaviors and exercise self-control in daily activities (Livneh \& Sherwood, 1991; Sawyer \& Crimando, 1984). In self-management training, students play an active role in every phase of the training or counseling process. Students are active participants whereby they augment the introspective and didactic aspects of training or counseling by developing specific action-steps (e.g., learning self-reinforcement techniques) and/or action-skills. Finally, in self-management training, teachers and counselors establish an increased mentor and reduced expert role (Gilliland, James, \& Bowman, 1994). Selfmanagement training is warranted when discrepancies are found between expectations and performance (e.g., appropriate behavior in a restaurant). The most utilized and empirically developed self-management techniques include antecedent cue regulation, self-instruction, selfmonitoring, and self-reinforcement (Rusch, Martin, \& White, 1985). Antecedent cue regulation consists of using pictures as visual cues with prompts to correct behavior, while self-instruction uses the individuals own verbal behavior to guide performance. Self-monitoring focuses on self-observation of behavior which results in systematic recording of behavior. Self-reinforcement (usually used in conjunction with self-monitoring) results in individuals reinforcing their own behavior.

Figure 1 provides an outline of one model for teaching self-instruction utilizing multiple exemplars. This model is a six-step instructional model developed by Hughes and Rusch (1992) that combines traditional self-instruction methods with teaching multiple exemplars as a means of promoting self-management skills across contexts in high school students with cognitive disabilities. Rehabilitation counselors who understand behavioral models such as this can be instrumental by providing direction to transition team members (i.e., teachers, instructional aids, and par- ents) who would likely administer the actual steps in the model.

Figure 1: Model for teaching self-instruction utilizing multiple examplars (Hughes \& Rusch, 1992, p. 213).

Figure 1:

Step 1: Select an array of examples (responses).

Step 2: Classify responses into teaching sets.

Step 3: Divide members of sets into trained responses and generalization probes.

Step 4: Teach trained responses using self-instruction.

Step 5: Evaluate the effect of training.

Step 6: Withdraw training and evaluate the effect of training withdrawal.

Step one requires the selection of an array of examples, however, classroom special education teachers may be unfamiliar with adult workplace examples and problem situations, therefore rehabilitation counselors should be able to contribute work or community related "problem situations" that employees are likely to encounter in a regular workday. For example a rehabilitation counselor might suggest a problem situation such as a mailroom clerk unable to deliver mail that has an illegible address, or perhaps an employee incapable of ordering lunch with coworkers in a nearby restaurant. These problem situations can then be systematically addressed through this model.

Hughes and Rusch (1992) discuss a variety of research using this model including a study by Graham and Harris (1989) in which three students with learning disabilities were taught to self-instruct in order to improve their expository writing. By teaching the students to "think out loud" through four self-instructional statements (i.e. defining the problem; planning the correct response; evaluating the response; and self-reinforcing) students improved their writing across key quality indicators. The effects were also generalized to different settings.

Hughes \& Rusch (1989) used this model to improve problem solving in work settings with two employees with disabilities. In this study, both trained and novel situations were used as performance criterion and the sequential withdrawal of training resulted in the maintenance of gains made in training at a six-month follow up. Most promising was that these gains were maintained without the need for direct instruction. Rehabilitation consumers transitioning from high school into supported employment settings may particularly benefit from this approach due to the constraints in long-term support dollars in many states which limit the amount of time and support available to employees with disabilities.

\section{Social Skills Training}

A second area in which applications of behavior therapy can assist persons with developmental disabilities to reach 
desired outcomes is through social skills training. Chadsey-Rusch (1992) defined social skills as,

goal oriented, rule governed, and learned behaviors that are situation specific and vary according to social context; they also involved both observable and non observable cognitive and affective elements that assist in evoking positive or neutral responses and avoiding negative responses from others (p. 6).

Facilitating successful employment outcomes is often a foundation of the rehabilitation counselor's role when assisting persons with developmental disabilities to obtain and maintain employment.

Why are social skills important in employment? A number of studies during the past 25 years have found that limited social skills in persons with mental retardation can profoundly impact their careers and lives, often playing a major role in the success or failure of job and social integration in competitive employment settings (Cavaiulo \& Nasca, 1991; Chadsey-Rusch, Gonzalez, Tines, \& Johnson, 1989; Foss \& Peterson, 1981; Heal, Gonzalez, Rusch, \& Copher, 1990; Hughes, Kim \& Hwange, 1998; Mueller, 1988). Chadsey-Rusch, Gonzalez, Tines, and Johnson (1989) examined social interaction patterns between eight persons with mental retardation and eight persons without mental retardation. The study found that co-workers without mental retardation interacted more with each other than among workers with mental retardation, and that workers without mental retardation engaged in significantly less nontask interactions (e.g., discussing sports, the weather, current events) among workers when compared to those without mental retardation. In a larger nationwide study, Heal, Gonzalez, Rusch, and Copher (1990) examined matched pairs of high school students and young adults with mental retardation who were both successful and unsuccessful in competitive employment. Social ability was among the most important elements listed by placement counselors, trainers, and supervisors.

In employment settings, social skills can overcome initial negative perceptions from supervisors and coworkers. Two categories of needed social skills for persons with developmental disabilities in employment settings include work-related social skills, such as performing tasks independently after a supervisor's instruction, and non-workrelated social skills, such as communicating with coworkers (Huange \& Cuvo, 1997). These areas are often a focus of social skills training.

The setting for social skills training has been an important area of research as it affects the level of difficulty in controlling the experiment, as well as impacting the generalization of the training to other settings. The advantages to social skills training in sheltered settings are that the study is easily controllable; however, generalization from sheltered settings to community-based settings is difficult at best (Huange \& Cuvo, 1997). Additionally, advantages to training in community-based settings are increased social integration opportunities as well as an increased likelihood of generalization across environments and situations. One major disadvantage of particular interest to rehabilitation professionals is that conducting social skills training in natural settings (e.g., work site) may interfere with competitive employment and be stigmatizing to the learner (Huange \& Cuvo, 1997). Therefore, it is crucial to select appropriate times and settings for social skills training (e.g., after work hours when coworkers are away).

Social skills training treatment procedures appropriate for people with developmental disabilities can be grouped into six categories which include: modeling; consequence management; social skills training packages; peer-mediated training; self-management training; and process training. All of these procedures are applicable to various rehabilitation settings, depending on consumer variables, counselor training, and environmental factors.

Modeling. Modeling can be conducted on a one-to-one basis or in a group format, making it a feasible treatment option for the rehabilitation counselor. Modeling has proven to be suitable for adults with severe to mild mental retardation and is relatively easy and efficient to administer. For example, Morgan and Salzberg (1992) illustrated the potential for adults with mental retardation to learn social skills via a video assisted modeling procedure. This procedure may be particularly useful in rural rehabilitation settings where transportation is a barrier to service provision. Their findings suggest that participants learned to request assistance, fix problems, and report problems to supervisors, when the specific behavior was modeled on the video. And, most importantly, training results are often generalizable to other specific problems after the training was completed. Factors the rehabilitation counselor should consider before engaging in modeling are his or her own expertise, relationship factors with the participant (e.g., authority issues), and the participant's unique background and experiences (e.g. cultural differences). Whenever possible it is also useful to use multiple models during the treatment.

Consequence management. Consequence management involves "defining an observable behavior, identifying antecedent and consequence events of that behavior, and applying consequences to that behavior consistently. The consequence may be either a positive or negative reinforcement (Huange \& Cuvo, 1997, p. 22). A limitation of this method is that it may generate an immediate improvement in the target behavior, however the improvement will generally last only as long as the controlling consequence is effective. Also, this approach is very specific to the target behavior and may neglect to address other important aspects of the participant's life.

Social skills training packages. Social skills training approaches marketed as "packages" can be useful tools in rehabilitation settings as they generally contain coordinated instruction, modeling, role-play, and social feedback elements. For example, the target behavior selected for the treatment may focus on teaching the consumer to respond appropriately to his or her supervisor's feedback. These packages provide counselors with a framework to model 
the correct response for the consumer, for the consumer to then practice the response, and finally for the counselor to provide feedback on the consumer's performance. This approach and others have been found to show improvement in changing the target behaviors (Andrasik \& Matson, 1985). Again, the primary disadvantage is that maintenance and generalization may not occur in other settings, situations, and contexts over time.

Peer-mediated strategies. Peer-mediated strategies are designed to be used with adults with developmental disabilities in integrated employment settings. Coworkers without disabilities are taught to interact with the participant in therapeutic and supportive ways (e.g., engaging the person with developmental disability in non-work related conversations). This approach promotes the use of natural supports in supported employment settings and has been found to be an effective way of reducing some maladaptive behaviors of participants (Rusch, Weithers, Menchetti, \& Schultz, 1980).

Baumgart and Askvig (1992) suggest managers and employees could provide appropriate strategies for remediating job-related social skills problems for adults with mild and moderate mental retardation or learning disabilities. This suggests rehabilitation counselors can include, and possibly rely on, motivated employers to help provide social skills training on the job. In doing so, employers may benefit from receiving information on individuals with disabilities as well as training on social skills interventions specific to the employee in need.

Self-management training. Self-management training, as previously reviewed in terms of its usefulness with adolescents, is also often combined with other procedures to teach effective social skills. Wheeler, Bates, Marshall, and Miller (1988) tested the effectiveness of a social skills training package with self-monitoring activities to reduce socially unacceptable behaviors and found that self-management training led to a reduction of the target behavior. Interestingly, the very nature of self-monitoring tends to produce a positive response in the subject and therefore has natural treatment effects (Huange \& Cuvo, 1997).

Okolo and Sitlington (1986) noted that failure to acquire good interpersonal skills might also be significantly related to the problems that youth with learning disabilities face when transitioning from high school to employment settings. One particular example of teaching self-management skills to adolescents with learning disabilities (Shapiro, 1989) was a study that examined changes in subjects' problem solving and job-related social skills.

Shapiro (1989) tested a self-management instruction method consisting initially of training students to understand their behavior in terms of antecedent-behavior-consequence $(A B C)$ relationships. Once students demonstrated an understanding of the basic $A B C$ relationships, self-management training began. The first skill taught was problem identification, followed by specific lessons on goal setting, self-monitoring, self-evaluation, and self-reinforcement. All units of instruction included multiple applications of self-management principles across the student's environments usually consisting of home, school, and work settings. The final element of the program applied self-management principles to job-related skills of resume' writing, job search, interviewing, and interpersonal skills on the job. Results showed significant and substantial improvements in students with learning disabilities who received the self-management training program compared to both students with and without learning disabilities that were not trained.

Process training. Process training relies on the participants understanding of the rules of social situations rather than learning a specific response to a specific situation. Therefore, it is not as effective with those with severe levels of cognitive impairment. However, because higher order thinking is required, it can lead to substantial improvement, generalization, and maintenance of social behaviors across various work settings. In process training, the participant is taught to decode and interpret cues in social contexts, identify and choose alternative behaviors for the situation, perform the behavior, and then evaluate the effectiveness of that behavior. The decoding, decision-making, performance, and self-evaluation components are taught using modeling, rehearsal, and feedback (Park \& Gaylord-Ross, 1989).

Chadsey-Rusch and O'Reilly (1992) developed a study to test the effectiveness of process training to teach question-asking to workers with mental retardation and found that all participants learned to perform the social skills process components and displayed generalization across all settings. An advantage of this approach is that it involved trainees as active participants in their learning by requiring them to think about and understand general rules. Another advantage to process training is that it has been proven to be more effective than the standard social skills training package which generally addresses coordinated instruction, modeling, role-play, and social feedback elements, or learning a specific response to a specific situation.

\section{Pragmatic Considerations in Using Behavior Therapy Interventions in Rehabilitation Settings}

Behavior therapy makes use of a skill-training orientation to therapy and adopts an educational model with an emphasis on teaching consumers how to cope with different problems. Though this approach has led to major breakthroughs (e.g., assertiveness training), there can be a tendency for rehabilitation counselors to lapse into a didactic and overly directive approach to intervention, thereby limiting the consumer's own voice and power.

Behavior therapy characteristically provides counselors with a "fine-grained" analysis of how individuals with developmental disabilities react to specific life situations. Rehabilitation counselors need to be aware that there can be a trade-off involved when they engage in a microscopic analysis of the consumer's behavior. The higher the mag- 
nification, the narrower the field of vision may become, thus the shortcoming of behavior therapy is the failure to look at the behavior patterns that may span different times and settings in a consumer's life.

Behavior therapy has typically been dedicated to the development and study of specific effective techniques such as self-management and social skills training. With the emphasis on techniques, the behavior therapy literature may lead to the conclusion that all counselors can adequately apply these methods to all consumers. It needs to be recognized that there is a tendency to undermine individual differences, which ultimately serves to undermine the effectiveness of the methods. Additionally, focusing only on techniques may result in overlooking the principle of change which may prevent considering and experimenting with techniques that might even be more effective in implementing the change principle.

When rehabilitation counselors maintain the primary focus of helping people live better lives by overcoming their impairments, behavior therapy can enhance the lives of persons with developmental disabilities. The evolution of behavior therapy research from institutional to clinical to community-based settings has resulted in the development of approaches useful to the rehabilitation counselor. More research on the ability of self-management skills and social skills training to generalize across time and settings may continue to provide the rehabilitation counselor with valuable tools to assist people with developmental disabilities to achieve greater success in living in the community.

\section{References}

Andrasik, F., \& Matson, J. L. (1985). Social skills training for the mentally retarded. In L. Abate \& M. A. Milan (Eds.), Handbook of social skills training and research (pp. 418454). New York: Wiley-Interscience.

Bandura, A. (1986). Social foundations of thought and action: $A$ social cognitive theory. Englewood cliffs, NJ: Prentice-Hall.

Baumgart, D., \& Askvig, B. (1992). Job-related social skills interventions: Suggestions from managers and employees. Education and Training in Mental Retardation, 27(4): 345353.

Braddock, D. (1998). Mental retardation and developmental disabilities: Historical and contemporary perspectives. In D. Braddock, R. Hemp, S. Parish, J. Westrich, J. (Eds.), The state of the states in developmental disabilities (5th ed.) (pp. 3-22). Washington, DC: American Association on Mental Retardation.

Braddock, D., Hemp, R., Parish, S., Westrich, J., \& Park, H. (1998). The state of the states in developmental disabilities: A summary of the studies. In D. Braddock, R. Hemp, S. Parish, J. Westrich, J. (Eds.), The state of the states in developmental disabilities (5th ed.) (pp. 23-54). Washington, DC: American Association on Mental Retardation.

Bradley, V. J., \& Knoll, J. (1990). Shifting paradigms in services to people with developmental disabilities. Cambridge, MA: Human Services Research Institute.

Cavaiulo, D., \& Nasca, M. (1991). The relevance of social survival skills in job retention of works with mental retardation. Vocational Evaluation and Work Adjustment Bulletin, 24(1), 27-31.
Chadsey-Rusch, J. (1992). Toward defining and measuring social skills in employment settings. American Journal on Mental Retardation, 69, 405-418.

Chadsey-Rusch, J., Gonzalez, P., Tines, J., \& Johnson, J. R. (1989). Social ecology of the workplace: Contextual variables affecting social interactions of employees with and without mental retardation. American Journal on Mental Retardation, 94, 141-151.

Chadsey-Rusch, J., \& O'Reilly, M. (1992). Social Integration in Employment and Postsecondary Educational Settings: Outcomes and Process Variables. In F. Rusch, L. Destefano, J. Chadsey-Rusch, A. L. Phelps, \& E. Szymanski (Eds.), Transition from school to adult life: Models, linkages, and policy (pp. 210-218). Pacific Grove, CA: Brooks/Cole Publishing Company.

Chadsey-Rusch, J., Rusch, F., \& O'Reilly, M. (1991). Transition from school to integrated communities. Remedial and Special Education, 12(6), 23-33.

Degeneffe, C. (2000). Supported employment services for persons with developmental disabilities: Unmet promises and future challenges for rehabilitation counselors. Journal of Applied Rehabilitation Counseling, 31(2), 41-47.

Education for All Handicapped Children Act of 1975, PL 94-142 (August 23, 1977). Title 20, U.S.C. 1400 et seq: U.S. Statutes at Large, 89, 773-796.

Eyenck, H.J. (1959). Learning theory and behavior therapy. Journal of Mental Science, 106, 61-75.

Foss, G. \& Peterson S.L. (1981). Social interpersonal skills relevant to job tenure for mentally retarded adults. Mental Retardation, 19(3), 103-106.

Heal, L.W., Gonzalez, P., Rusch, F. R., \& Copher, J. (1990). A comparison of successful and unsuccessful placements of youths with mental handicaps into competitive employment. Exceptionality, 1(3), 181-195.

Chadsey-Rusch, J., Gonzalez, P., Tines, J., Johnson, J.R. (1989). Social ecology of the workplace: Contextual variables affecting social interactions of employees with and without mental retardation. American Journal on Mental Retardation, 94(2): 141-151.

Graham, S., \& Harris, K.R. (1989). Improving learning disabled students' skills at composing essays: Self-instructional strategy training. Exceptional Children, 56, 201-214.

Gilliland, B., James, R., \& Bowman, J. (1994). Theories and strategies in counseling and psychotherapy education. Needham Heights, MA: Allyn and Bacon.

Heighway, S., Kidd Webster, S., \& Shaw, M. (1992). STARS: Skills training for assertiveness, relationship-building and sexual awareness (3rd ed.). Madison, WI: Wisconsin Council on Developmental Disabilities.

Huange, W., \& Cuvo, A. J. (1997). Social skills training for adults with mental retardation in job-related settings. Behavior Modification, 21(1), 3-33.

Hughes, C., Kim, J.H., \& Hwange, B. (1998). Assessing social integration in employment settings: Current knowledge and future directions. American Journal on Mental Retardation, $103(2), 173-185$

Hughes, C., \& Rusch, F. (1989). Teaching supported employees with severe mental retardation to solve problems. Journal of Applied Behavior Analysis, 22, 365-372.

Hughes, C., \& Rusch, F. (1992). Behavior-management strategies for school-work community. In F. Rusch, ChadseyRusch, J., \& Szymanski, E. (1992). Transition from school to adult life. Sycamore, IL: Sycamore Publishing Company.

Lakin, K. C., Bruininks, R. H., Larson, S. A. (1992). The changing face of residential services. In L. Rowitz (Ed.), Mental retardation in the year 2000, (pp. 197-250). New York: Springer-Verlag. 
Lakin, K. C., \& Smull, M. (1995). Supported community living: From "facilities" to "homes." Impact, 8(4), 2-3.

Livneh, H., \& Sherwood, A. (1991). Application of personality theories and counseling strategies to clients with physical disabilities. Journal of Counseling and Development, 69, 525-540.

Mandeville, H. (1990). Supported parenting: Finding a home in the service system. Madison: Wisconsin Council on Developmental Disabilities.

Matson, J. L., \& Gardner, W. I. (1991). Behavioral learning theory and current applications to severe behavior problems in persons with mental retardation. Clinical Psychology Review, 12, 369-382.

Morgan, R. L., \& Salzberg, C. L. (1992). Effects of video-assisted training on employment related social skills of adults with severe mental retardation. Journal of Applied Behavior Analysis, 25, 265-383.

Mueller, H. H. (1988). Employer's reasons for terminating the employment of workers in entry-level jobs: Implications for workers with mental disabilities. Canadian Journal of Rehabilitation 1(4), 233-240.

Nezu, C. M., \& Nezu, A. M. (1994). Outpatient psychotherapy for adults with mental retardation and concomitant psychopathology: research and clinical imperatives. Journal of Consulting and Clinical Psychology, 62(1), 34-42.

Olney, M. F., \& Salomone, P. R. (1992). Empowerment and choice in supported employment: Helping people to help themselves. Journal of Applied Rehabilitation Counseling," 23(3), $41-44$.

Okolo, C. M., \& Sitlington, P. (1986). The role of special education in LD adolescents' transition from school to work. Learning Disability Quarterly, 9, 141-155.

Park, H., \& Gaylord-Ross, R. (1989). A problem-solving approach to social skills training in employment settings with mentally retarded youth. Journal of Applied Behavior Analysis, 22, 373-380.

Parker, R. M., \& Szymanski, E. M. (1998). Rehabilitation counseling: basics and beyond. (3r ed.). Austin, TX: PRO-ED.

Phelps, L. A., \& Hanley Maxwell, C. (1997). School-to-work transitions for youth with disabilities: A review of outcomes and practices. Review of Educational Research, 67(2), 197226.

Pope, A. M., \& Tarlov, A. R. (Eds.). (1991). Disability in America: Toward a national agenda for prevention. Washington, DC: National Academy Press.

Rice, J. (1985). A behavioral perspective. Journal of Applied Rehabilitation Counseling, 16(3), 26-29.

Rickard, H. C., Thrasher, K. A., \& Elkins, P. D. (1984). Responses of persons who are mentally retarded to four components of relaxation instruction. Mental Retardation, 22, 248-252.

Rubin, S. E. \& Roessler, R. T. (1995). Foundations of the vocational rehabilitation process-(4th ed.). Austin: Pro-Ed.

Rusch, F. R., Martin, J. E., \& White, D. M. (1985). Competitive employment: Teaching mentally retarded employees to maintain their work behavior. Education and Training of the Mentally Retarded, 20, 182-189.

Rusch, F.R., Weithers, J.A., Menchetti, B.M. \& Schutz, R.P. (1980). Social validation of a program to reduce topic repetition in a nonsheltered setting, 15, 208-215.

Sands, D. J., \& Wehmeyer, M. L. (1996). Self-determination across the life span: Independence and choice for people with disabilities. Baltimore, Maryland: Paul H. Brooks Publishing Co.

Sawyer, H. W., \& Crimando, W. (1984). Self-management strategies in rehabilitation Journal of Rehabilitation, 50, 2730.

Schriner, K.F., Roessler, R.T., \& Johnson, P. (1993). Identifying the employment concerns of people with spina bifida. Journal of Applied Rehabilitation Counseling 24(2), 32-37.

Shafer, M.S. (1989). An introduction to supported employment. In P. Wehman and J. Kregel (Eds.), Supported employment for persons with disabilities (pp. 3-18). New York: Human Sciences Press.

Shapiro, E. (1989). Teaching self-management skills to learning disabled adolescents. Learning Disability Quarterly, 12, 275287.

Smull, M. W., \& Danehey, A. J. (1994). Increasing quality while reducing costs: The challenge of the $1990 \mathrm{~s}$. In V. J. Bradley, J. W. Ashbaugh, B. C. Blaney (Eds.), Creating individual supports for people with developmental disabilities: A mandate for change at many levels (pp. 421-433). Baltimore, $M D$ : Paul H. Brookes Publishing Co.

U.S. Department of Education. (2000). Twenty-second annual report to congress on the implementation of the Individuals with Disabilities Education Act. Washington DC: Office of Special Education Programs.

U.S. Department of Health and Human Services. (1999). The Developmental Disabilities Assistance and Bill of Rights Act. Retrieved from the World Wide Web: http://www. acfdhhs.gov/programs/add/dd-act.htm. April 28, 1999.

Wheeler, J. J., Bates, P., Marshall, K. J., \& Miller, S. R. (1988). Teaching appropriate social behaviors to a young man with moderate mental retardation in supported competitive employment setting. Education and Training in Mental Retardation, 23, 105-166.

Whitman, T. L. (1990). Self-regulation and mental retardation. American Journal of Mental Retardation, 94, 347-363.

Wilson, G.T. (1995). Behavior Therapy. In R.J. Corsini \& D. Wedding (Eds.), Current Psychotherapies (pp.197-228). Itasca, Illinois: F.E. Peacock Publishers, Inc.

Wolfensberger, W. (1977). A brief overview of the principle of normalization. In S. A. Grand (Ed.), Severe disability and rehabilitation counselor training (pp. 7-24). Albany: State University of New York at Albany.

York, J. \& Tundidor, M. (1995). Issues raised in the name of inclusion: Perspectives of educators, parents, and students. TASH, 20 (1), 31-44.

Tina Anctil is a Ph.D. candidate in Rehabilitation Psychology at the University of Wisconsin-Madison. She has worked as a rehabilitation counselor for the Oregon Vocational Rehabilitation Division and is currently practicing as a child and family psychology intern at the Mental Health Center of Dane County. Her research interests include self-determination, high school transition, and the impact of disability on families.

Charles Degeneffe, Ph.D., is an Assistant Professor in the Rehabilitation Counseling Program at California State University, Fresno. Dr. Degeneffe's academic interests include family caregiving, traumatic brain injury, supported employment, and Gestalt therapy. 